\title{
Hand hygiene intervention to optimise soil- transmitted helminth infection control among primary school children: the Mikono Safi cluster randomised controlled trial in northwestern Tanzania
}

Kenneth Makata ${ }^{1}$, Jeroen Ensink ${ }^{2}$, Philip Ayieko ${ }^{1,2,3}$, Christian Hansen ${ }^{1,2}$, Simon Sichalwe ${ }^{1}$, Julius Mngara ${ }^{3}$, Onike Mcharo ${ }^{1}$, Humphrey Mazigo ${ }^{4}$, Jeremiah Seni ${ }^{5}$, Robert Dreibelbis ${ }^{2}$, Sarah Rockowitz ${ }^{6}$, Elialilia Okello ${ }^{1}$, Heiner Grosskurth ${ }^{1,2,3}$, Safari Kinung' hi $^{3}$ and Saidi Kapiga ${ }^{1,2,3^{*}}$ (D)

\begin{abstract}
Background: Soil-transmitted helminth (STH) infections are highly prevalent in resource-limited countries. We assessed the effect of a combination intervention aiming to enhance handwashing with soap on STH reinfection following mass drug administration among primary school children in Kagera region, Northwestern Tanzania.

Methods: We conducted a cluster randomised trial in sixteen primary schools with known high STH prevalence. Schools were randomly assigned in a 1:1 ratio to either receive the intervention or continue with routine health education. The intervention included teacher-led classroom teaching, parental engagement sessions, environmental modifications and improved handwashing stations. The evaluation involved two cross-sectional surveys in a representative sample of students, with the end-line survey conducted 12 months after the baseline survey. The primary outcome was the combined prevalence of Ascaris lumbricoides and Trichuris trichiura infections at the endline survey. Secondary outcomes included reported handwashing behaviour, the prevalence and intensity of individual STHs, and hand contamination with STH ova and coliform bacteria. End-line STH prevalence and intensity were adjusted for baseline differences of potential confounders.

(Continued on next page)
\end{abstract}

\footnotetext{
* Correspondence: saidi.kapiga@lshtm.ac.uk

Jeroen Ensink is deceased.

${ }^{1}$ Mwanza Intervention Trials Unit (MITU), Mwanza, Tanzania

${ }^{2}$ London School of Hygiene and Tropical Medicine, London, UK

Full list of author information is available at the end of the article
}

C The Author(s). 2021 Open Access This article is licensed under a Creative Commons Attribution 4.0 International License, which permits use, sharing, adaptation, distribution and reproduction in any medium or format, as long as you give appropriate credit to the original author(s) and the source, provide a link to the Creative Commons licence, and indicate if changes were made. The images or other third party material in this article are included in the article's Creative Commons licence, unless indicated otherwise in a credit line to the material. If material is not included in the article's Creative Commons licence and your intended use is not permitted by statutory regulation or exceeds the permitted use, you will need to obtain permission directly from the copyright holder. To view a copy of this licence, visit http://creativecommons.org/licenses/by/4.0/. The Creative Commons Public Domain Dedication waiver (http://creativecommons.org/publicdomain/zero/1.0/) applies to the data made available in this article, unless otherwise stated in a credit line to the data. 
(Continued from previous page)

Results: At the end-line survey, 3081 school children (1566 from intervention schools and 1515 from control schools) provided interview data and stool specimens. More school children in the intervention group reported the use of water and soap during handwashing compared to school children in the control group (58\% vs. 35\%; aOR=1.76, 95\% Cl 1.28-2.43, $p=$ 0.001). The combined prevalence of $A$. lumbricoides and T. trichiura infections was 39\% in both trial arms $(\mathrm{aOR}=1.19 ; 95 \% \mathrm{Cl}$ 0.74-1.91). The prevalence of $A$. lumbricoides was $15 \%$ in the intervention and $17 \%$ in the control arm $(\mathrm{aOR}=1.24,95 \% \mathrm{Cl}$ 0.59-2.59) and that of T. trichiura was 31\% in both arms ( $\mathrm{aOR}=1.17,95 \% \mathrm{Cl} 0.73-1.88$ ). No significant differences were found for STH infection intensity in both the main study and the hand contamination sub-study.

Conclusions: The intervention was effective in increasing reported handwashing behaviour at school, but failed to show a similar effect in the home. The intervention had no effect on STH infection, possibly due to infection in the home environment, other transmission routes such as contaminated water or food or limited changes in school children's handwashing behaviour.

Trial registration: The trial was registered on June 21, 2017, by the International Standard Randomised Controlled Trial Number (ISRCTN45013173).

Keywords: Soil-transmitted helminth, Ascaris lumbricoides, Trichuris trichiura, Mass drug administration, Deworming, Hand hygiene, Handwashing, School children, Cluster randomised trial, Tanzania

\section{Background}

Soil-transmitted helminth $(\mathrm{STH})$ infections are a major global health problem, with more than one billion people estimated to be affected worldwide [1]. The infections are particularly frequent among school children in low- and middle-income countries (LMICs) in whom they are associated with anaemia and impaired physical and cognitive development $[2,3]$. Deworming by using anti-helminthic drugs as part of regular mass drug administration (MDA) is advocated by WHO as a strategy for STH control in high prevalence areas in LMICs [1]. In Tanzania, annual MDA campaigns are conducted in primary schools as part of the national neglected tropical diseases (NTD) control programme [4]. However, STH prevalence remains high in many communities [5, 6] as MDA is often followed by rapid re-infection [7]. Poor water, sanitation and hygiene (WASH) practices have been proposed as a likely explanation [8].

The role of handwashing with soap in preventing STH transmission is yet to be established given inconsistent results from recent studies. A systematic review and meta-analysis reported in 2014 suggested that hand hygiene or other individual WASH interventions may reduce the odds of STH reinfection following deworming by 33-70\% [9]. However, a more recent review reported inconsistent findings, with hand hygiene effectiveness ranging from zero to $59 \%$ [10]. None of the studies included in this review assessed the effect of handwashing with soap alone as a single intervention on STH re-infection after treatment.

We conducted a cluster randomised trial to assess the effect of a combination intervention aiming to enhance handwashing with soap on STH re-infection following MDA among primary school children in Kagera region, northwestern Tanzania. This region has high prevalence of Ascaris lumbricoides and Trichuris trichiura infections, which are species of STH known to be transmitted predominantly through the oral ingestion of worm eggs $[5,6]$.

\section{Methods}

\section{Study setting and population}

Kagera region is situated on the western shores of Lake Victoria, neighbouring Rwanda and Burundi to the West and Uganda to the North. Based on the national census, Kagera had a population of about 2.5 million by 2012, with an annual inter-census growth rate of $3.2 \%$ [11]. The primary school system is mainly public, with high rate of school enrolment especially in urban areas, ranging from 85 to $90 \%$ [12]. All major villages of the region have at least one public primary school which comprises of grades 1 to 7 , with the number of students aged 6-12 years ranging from 500 to 1500 children per school.

The trial was conducted in 16 public primary schools purposely selected from a total of 51 schools assessed prior to study initiation to establish eligibility. The schools were located in 3 out of 8 districts in the region (Bukoba urban, Bukoba rural and Muleba) which were chosen because they were easily accessible from the project office in Bukoba town. The schools were selected based on pre-determined criteria: a pre-trial prevalence of Ascaris lumbricoides and/or Trichuris trichiura infections of at least $20 \%$, access to water within the school premises, and for logistical reasons a school size of less than 1200 students.

\section{Study design and data collection}

This was a cluster-randomised controlled trial (c-RCT) using primary schools as randomisation units. Eight schools each were allocated to the intervention and control arms (Fig. 1). Randomisation was restricted to 
ensure a balanced distribution of schools across the two trial arms with respect to district location and level of pre-trial STH prevalence. Details on the study design and randomisation process have been described previously [13].

\section{Study objective and outcomes}

The study aimed to determine the effectiveness of the Mikono Safi handwashing intervention on sustaining the prevalence of STH infections observed after performing routine deworming as part of the national MDA programme. 'Mikono Safi' means 'clean hands' in Kiswahili, the national language spoken in Tanzania. The primary outcome was defined as the combined prevalence of Ascaris lumbricoides and Trichuris trichiura infection at the end-line survey conducted 12 months after the intervention had been introduced in the intervention schools. Secondary outcomes included the prevalence and infection intensity of each STH infection, the prevalence of hand contamination with STH ova, Escherichia coli and other coliform bacteria, and the prevalence of reported handwashing behaviour.

\section{Intervention components}

Details of the intervention and its implementation have been described elsewhere [13]. Briefly, the intervention comprised 3 components: health education of children to promote handwashing with water and soap, a one-off engagement meeting with parents at school to obtain their support and modest modification of the physical environment at schools to facilitate handwashing. Health education was delivered using specifically designed teaching materials in three teacher-led sessions given during the course of 1 year. The sessions combined classroom lessons and handwashing demonstrations and games. We aimed to increase parents' emotional engagement and support by sharing and discussing pre-trial stool test results on STH

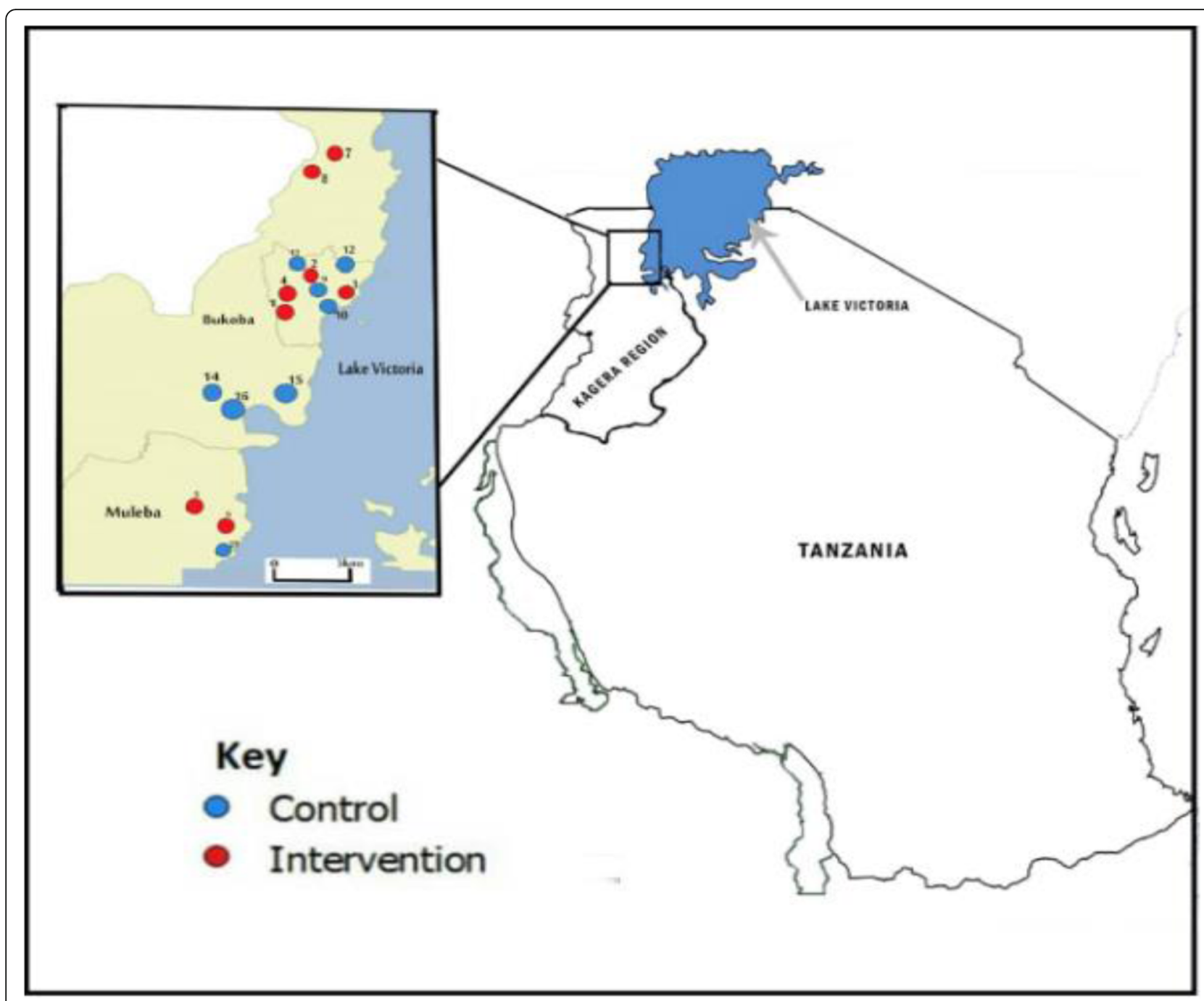

Fig. 1 Geographical location and randomisation status of the participating primary schools in Kagera region, Tanzania 
infections of their own children. For this exercise, stool samples were collected and rapidly analysed under field laboratory conditions using the Kato-Katz method. At schools, user friendly handwashing facilities were installed in close proximity to schools' latrine buildings [14]. We also marked the paths linking latrines with the near-by handwashing stations and painted brightly coloured nudges on the water containers to sub-consciously influence students' handwashing behaviour [15, 16] (Fig. 2). The design of the intervention had been informed by formative research conducted prior to the trial [17]. Schools in the control arm had access to water for handwashing and continued with routine health education as per national curriculum.

\section{Design of the evaluation}

In each school, two cross-sectional surveys were conducted, a baseline survey from November 2017 to June 2018 and an end-line survey 12 months later. In each survey, we aimed to enrol 1680 students from each trial arm, an average of 210 students from each school, stratified by sex and grade. Separate independent samples of students were enrolled at baseline and end-line surveys. Interviewer administered questionnaires were used to collect information on socio-demographic characteristics, handwashing practices while at home and school, sources of drinking water, water treatment and food preservation practices, type of household latrine and other risk factors for STH infection in the home environment. Data from both surveys were recorded directly onto tablet computers with in-built checks to minimise errors. Data were uploaded daily to a secure database and checked by the data manager.
In all study schools, a school-wide MDA was conducted using a single oral dose of $400 \mathrm{mg}$ of albendazole in line with the national NTD programme guidelines [4]. Two weeks later, we conducted the baseline survey at which randomly selected students were requested to provide a stool specimen for the detection of STH ova. Retreatment was provided to all students who were still found infected on this occasion. This approach was chosen in keeping with the study protocol [13] to help determine the level of STH infections remaining at the point when the intervention package was about to be implemented and ensure that infections detected at the end-line survey were likely due to reinfections. This allowed the impact of the intervention on sustaining the effects of deworming to be established by comparing the prevalence of infections in the two trial arms at end-line survey. This approach also provided data which was used to adjust for potential baseline imbalances in remaining infections in the analysis.

In addition, a sub-study was conducted to assess levels of hand contamination with faecal bacteria and STH ova in a randomly selected $20 \%$ sample of students who took part in the end-line survey. A total of 672 students were enrolled, 336 from each arm stratified by sex and grade, about 40 per school. Students were asked to wash and brush their hands and nails within a sterile polythene bag (Biodegradable Falcon zipper bags, Falconpack ${ }^{\circ}$, U.A.E) containing $100 \mathrm{ml}$ of isotonic saline. These hand rinse water samples were collected after students had spent about $2 \mathrm{~h}$ attending routine activities in school. The samples were sent to the nearby Bukoba regional referral hospital's laboratory for the detection of helminth ova, faecal coliforms and Escherichia coli.

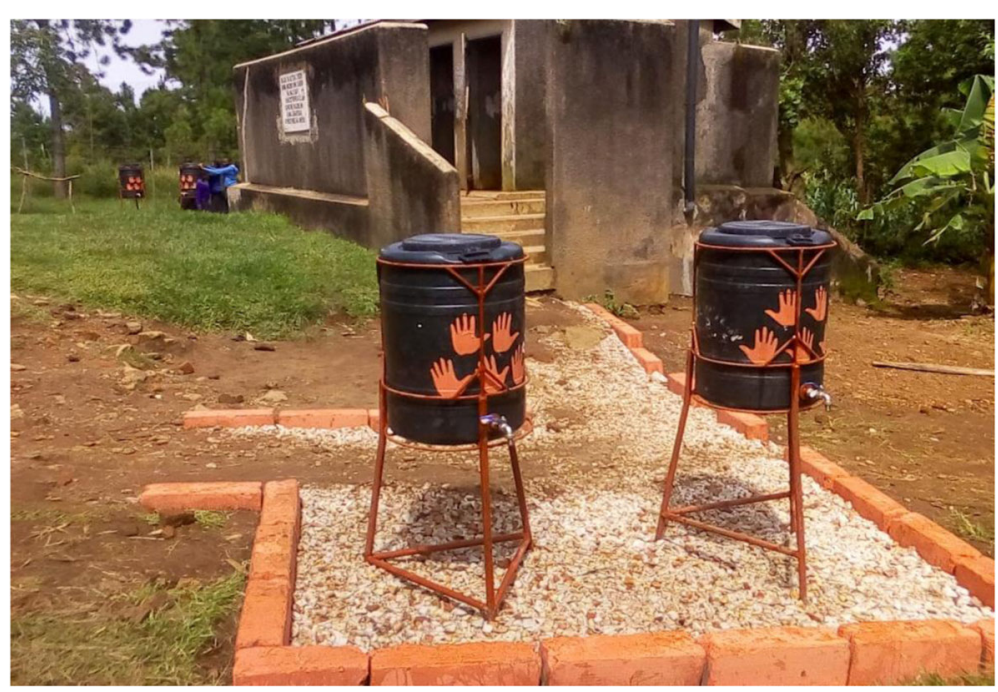

Fig. 2 Path between toilets and hand washing facility with nudges 


\section{Laboratory methods}

Stool specimens were preserved in $10 \%$ formalin at room temperature in sealed containers and transported to the central laboratory in Mwanza for analysis. Specimens were analysed using the formol-ether concentration method to identify helminth ova as this approach has shown high sensitivity even in populations with low infection intensity as could be expected in schools participating in annual deworming [18]. Infection intensity was assessed microscopically. Briefly, $1 \mathrm{~g}$ of stool sample was placed in a mortar and $10 \mathrm{ml}$ of $10 \%$ formal saline was added. The stool sample was homogenised by grinding. The homogeneous solution was filtered using a funnel with gauze into a test tube $(10 \mathrm{ml})$ and $2 \mathrm{ml}$ of ether was added. The resultant solution was mixed vigorously and then centrifuged at $3000 \mathrm{rpm}$ for $5 \mathrm{~min}$. After centrifugation, the floating debris was removed using an applicator stick, the supernatant discarded to remain with the sediment at the bottom of the test tube. The sediment was examined under light microscope (first at $\times 10$ magnification and then at $\times 40$ magnification) by taking one drop of sediment at a time, placing on a microscopic slide and covering by a cover slip. All helminth ova were examined and counted until the whole sediment was completed.

For safety reasons, diethyl ether solvent was replaced by ethyl-acetate, which has been shown not to affect the results [19]. Each specimen was examined by two independent qualified laboratory technologists. Specimens with discrepant results were reviewed with consultation among the two by a third reader. Quality control was performed on $10 \%$ of randomly selected samples and a repeated examination was performed by the same technologists without knowledge of their initial results.

For bacteriological analysis, $1 \mathrm{~mL}$ from each hand rinse water sample was taken using a sterile Pasteur pipette and placed into $9 \mathrm{~mL}$ of Brain Heart Infusion Broth (BHI; HI Media ${ }^{\circ}$ India). Samples were processed in the laboratory within $2-3 \mathrm{~h}$ after collection by inoculating them onto MacConkey agar w/0.15\% bile salt, CV and $\mathrm{NaCl}$ (HI Media ${ }^{\circ}$, India) using a calibrated $1 \mu \mathrm{L}$ loop. The plates were incubated at $35^{\circ} \mathrm{C}$ to $37^{\circ} \mathrm{C}$ for 18 to 24 h. The absolute numbers of colonies detected on the MacConkey agar plates (both lactose and non-lactose fermenting colonies) were multiplied by 1000 to get the corresponding number of coliforms $\mathrm{CFU} / \mathrm{ml}$. The resulting value was also multiplied by 10 taking in account the 1:10 sample to BHI dilution to get the final total coliforms CFU/ml. Escherichia coli was confirmed using conventional biochemical identification tests, and the total Escherichia coli CFU/ml was enumerated [20] and categorised into mild $\left(\leq 9 \times 10^{3} \mathrm{CFU} / \mathrm{ml}\right)$, moderate $(10-$ $\left.99 \times 10^{3} \mathrm{CFU} / \mathrm{ml}\right)$ and high $\left(\geq 100 \times 10^{3} \mathrm{CFU} / \mathrm{ml}\right)$ intensities.
For the identification and quantification of helminth ova, $10 \mathrm{ml}$ of the main hand rinse water sample was processed using the zinc sulfate centrifugal flotation method and examined by light microscopy for presence of STH eggs [21]. Helminth ova observed were quantified as described above.

\section{Statistical analysis}

Sample size calculations were informed by data from the pilot survey which showed that combined prevalence of Ascaris lumbricoides and Trichuris trichiura infection was $30 \%$ in pilot schools with a between-school coefficient of variation $(\mathrm{k})$ of 0.3 . The calculations assumed that 1 year after the deworming campaign the combined prevalence of Ascaris lumbricoides and Trichuris trichiura infection in the control arm would have reached the original level of $30 \%$ seen during the pilot conducted in the absence of a handwashing intervention. We determined that with a between-school coefficient of variation of 0.3 , a total of 3200 participants across 16 primary schools ( 200 participants per school), would provide at least $80 \%$ and $95 \%$ power to show intervention effects of $40 \%$ and $50 \%$ relative reduction in combined helminth infection, respectively.

Data analysis was performed using STATA version 14.2, following a pre-specified analysis plan, by analysts who were blind to the trial group allocation. Descriptive analysis of the characteristics of clusters and individual participants was conducted for each trial arm and overall. The medians and interquartile ranges were calculated for participants' age and reported as a continuous variable while frequency counts (percent) were calculated for categorical variables.

The primary analysis was conducted following the intention-to-treat (ITT) principle, with participants analysed according to the trial arm to which they were randomly allocated. All participants who were interviewed and provided a stool sample during the end-line survey were included in the analysis. The effect of the intervention on the primary outcome, i.e., the combined prevalence of Ascaris lumbricoides and Trichuris trichiura infection, was analysed in two stages. First a cluster level summary of the primary outcome was calculated for each school, and then, the means of the cluster summaries were compared between trial arms using an independent sample $t$ test [22]. For the primary outcome, the cluster level summary represented the residuals of adjusted log odds of infection obtained from logistic regression with Ascaris lumbricoides and Trichuris trichiura infection as outcome and adjusting for covariates measured at baseline that were possibly associated with STH infection at the end-line survey. Two-sided $p$ values and $95 \%$ confidence intervals $(95 \% \mathrm{CI})$ were computed from the $t$ test comparison of the mean adjusted 
log odds residuals of infection. The corresponding adjusted odds ratios (95\% CI) were obtained using exponentiation. This two-stage analysis was repeated for categorical secondary outcomes and the categorical outcomes in the hand contamination sub-study.

We used the quantitative egg count variable rather than the categorical variable (low, moderate, high) for assessment of the impact of the intervention on the intensity of helminth infection. The effect of the intervention on this quantitative outcome and on bacterial count (in the hand contamination sub-study) was assessed using a log-linear model, assuming a negative binomial distribution with a log link in the first stage followed by $t$ test comparison of mean residuals in the second stage. The corresponding adjusted rate ratio (and 95\% confidence interval) for quantitative outcomes was obtained by exponentiation of the mean differences from the $t$ test.

\section{Results}

The individual follow-up time per school was about 12 months. Sixteen eligible primary schools were randomised to the intervention arm (8 schools, total number of school children=4872) or the control arm (8 schools, total number of school children=4607) (Table 1). During the baseline survey, 3026 school children participated in the interviews and contributed stool specimens (1519 from the intervention arm and 1507 from the control arm). During the end-line survey, 1566 out of 1680 (93.2\%) school children in the intervention arm and 1515 out of 1680 (90.2\%) school children in the control arm contributed both interview data and stool samples and were included in the ITT analysis (Fig. 3).

As expected due to the study design, the number of participants was balanced with regard to gender and students' age during both baseline and follow-up surveys (Table 2). The combined prevalence of Ascaris lumbricoides and Trichuris trichiura was 35\% in both trial arms, determined 2 weeks following deworming campaigns. The prevalence of Ascaris lumbricoides alone was $0.4 \%$ and $3.1 \%$ in the intervention and control arms, respectively, while for Trichuris trichiura, it was 35\% and $34 \%$, respectively. Some imbalances were noted at baseline with regard to factors that could influence the risk of STH infection, but the direction of these differences did not consistently favour one of the trial arms: fewer children in the control arm reported handwashing after using the toilet ( $37 \%$ vs. $71 \%$ ), households' access to piped water was more frequent in the control arm (35\% vs 25\%), and more children in the control arm reported handwashing before eating (58\% vs. $38 \%$ ).

End-line survey results largely mirrored those from the baseline survey (Table 2). The majority of the school children lived with both parents $(65 \%$ and $62 \%$ in intervention and control groups, respectively). The majority of parents worked as farmers or were engaged in small scale businesses. Almost all participants reported to have a latrine at home and most of these (78\%) were pit latrines. Having had at least one episode of diarrhoea during the past 7 days preceding the interview was reported by about $23 \%$ of the children. About $40 \%$ recalled that they had ever eaten soil and about $48 \%$ reported to have ever observed worms during defecation.

In Table 3, we present the effect of the handwashing intervention on STH prevalence, infection intensity and reported handwashing behaviour during the end-line survey. The proportion of participants who reported to have used water and soap when they last washed their hands was $58 \%$ in the intervention arm and $35 \%$ in the control arm $(\mathrm{aOR}=1.76,95 \% \mathrm{CI} 1.28-2.43, p=0.001)$ (Table 3). When students were asked about the last time they washed hands at school, the use of water and soap was reported by $72 \%$ of children in the intervention arm and $39 \%$ in the control arm $(\mathrm{aOR}=3.7$, 95\% CI 1.35-10.15, $p=0.002)$. When asked about the

Table 1 Characteristics of clusters randomised to the intervention or control arm of the Mikono Safi trial, Kagera region, Tanzania

\begin{tabular}{llll}
\hline & Intervention & Control & \multicolumn{1}{c}{ Total } \\
\hline Number of participating clusters (schools) & 8 & 8 & 4607 \\
Total number of children enrolled in participating schools & 4872 & 576 \\
$\begin{array}{l}\text { Mean number of children per school } \\
\text { Number of schools located in: }\end{array}$ & 609 & 4 & 592 \\
Bukoba Municipality & & 3 & 8 \\
Bukoba rural & 4 & 1 & 3 \\
Muleba & 2 & 2 & 3 \\
Source of school water supply & 2 & 5 \\
$\quad$ Number of school supplied with piped water & 5 & 3 \\
Number of schools using rain water & 3 & 3
\end{tabular}

${ }^{a}$ One-half of the schools in the trial and in each arm were located in the urban municipality and the remaining half in rural area 


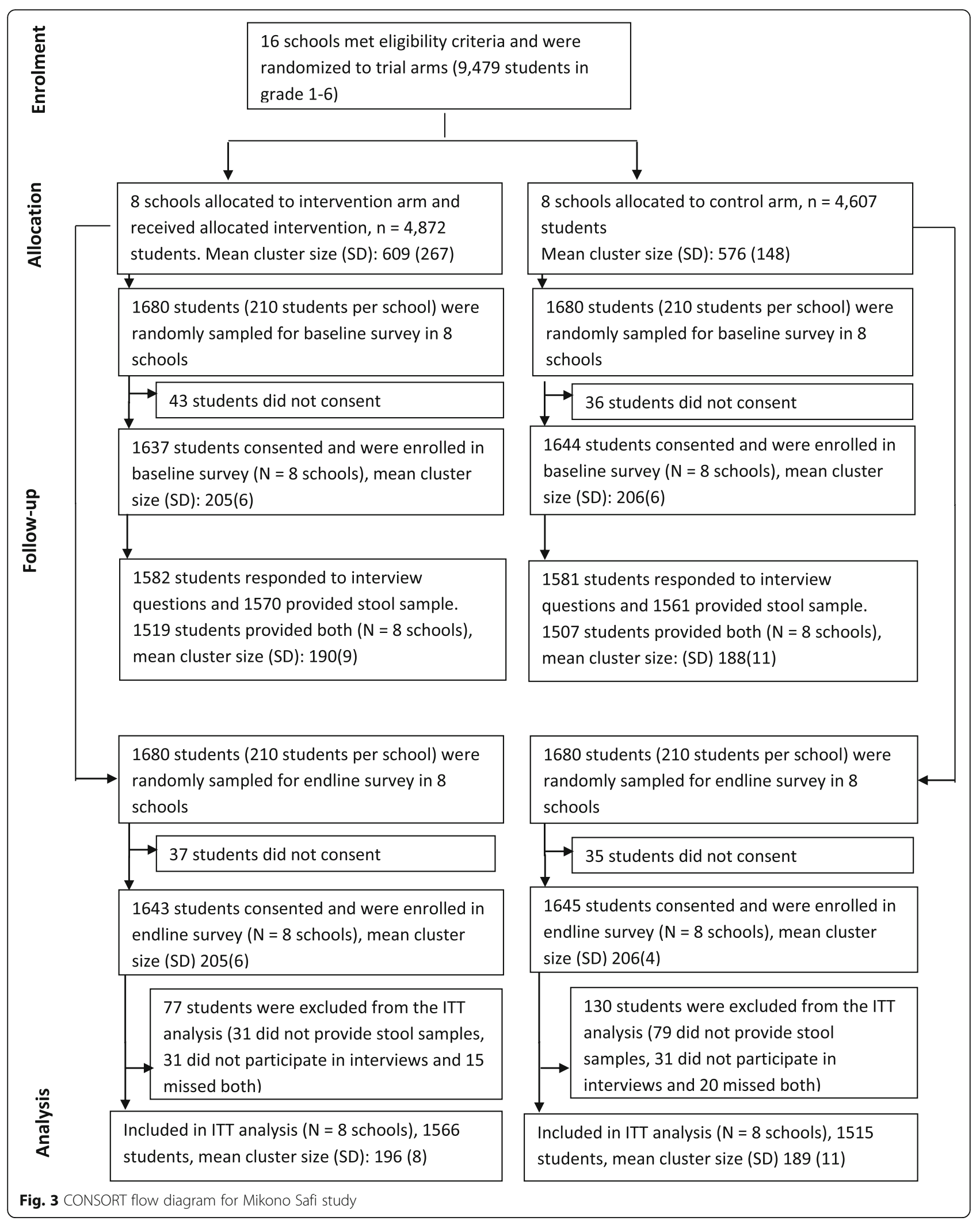


Table 2 Characteristics of individual participants within the clusters randomised to the intervention or control arm of the Mikono Safi trial, Kagera region, Tanzania

\begin{tabular}{|c|c|c|c|}
\hline & Intervention $n$ (\%) & Control $n(\%)$ & Total $n(\%)$ \\
\hline \multicolumn{4}{|l|}{ Baseline survey } \\
\hline Number of participants at baseline & 1582 & 1581 & 3163 \\
\hline Median [IQR] age of participants in years & $10(8-12)$ & $10(8-12)$ & $10(8-12)$ \\
\hline Female sex & $807(51)$ & $809(51)$ & $1616(51)$ \\
\hline \multicolumn{4}{|l|}{ Household possessions } \\
\hline Farm/land & $1500(96)$ & $1346(89)$ & $2846(92)$ \\
\hline Cow(s)/pig(s)/goat(s)/sheep & $805(51)$ & $774(51)$ & $1579(51)$ \\
\hline Television & $957(61)$ & $1010(67)$ & $1967(64)$ \\
\hline Gas/electric cooker & $586(37)$ & $743(49)$ & $1329(43)$ \\
\hline Mobile phone(s) & $1508(96)$ & $1461(96)$ & $2969(96)$ \\
\hline Bicycle & $482(31)$ & $516(34)$ & $998(32)$ \\
\hline Motor cycle & $280(18)$ & $385(25)$ & $665(22)$ \\
\hline Vehicle/tractor/boat & $379(24)$ & $356(23)$ & $735(24)$ \\
\hline \multicolumn{4}{|l|}{ Main source of water at home } \\
\hline In-house piped water & $166(10)$ & $282(18)$ & $448(14)$ \\
\hline Public owned piped water & $239(15)$ & $264(17)$ & $503(16)$ \\
\hline Well & $99(6)$ & $117(7)$ & $216(7)$ \\
\hline River/stream & $1040(66)$ & $920(58)$ & $1960(62)$ \\
\hline Lake & $51(3)$ & $10(1)$ & $61(2)$ \\
\hline Water vendor & $41(3)$ & $38(2)$ & $79(3)$ \\
\hline Other sources & $47(3)$ & $38(2)$ & $85(3)$ \\
\hline \multicolumn{4}{|l|}{ Reason for handwashing the last time participant washed hands } \\
\hline Had visited the toilet & $1119(71)$ & $583(37)$ & $1702(54)$ \\
\hline Washed before eating & $608(38)$ & $918(58)$ & $1526(48)$ \\
\hline Participant reported ever eating soil & $523(33)$ & $575(36)$ & $1098(35)$ \\
\hline \multicolumn{4}{|l|}{ Soil-transmitted helminth infection at baseline } \\
\hline Ascaris infection & $6(0.4)$ & $49(3.1)$ & $55(1.8)$ \\
\hline Trichuris infection & $543(35)$ & $529(34)$ & $1072(34)$ \\
\hline Hookworm infection & $7(0.45)$ & $12(0.77)$ & $19(0.61)$ \\
\hline \multicolumn{4}{|l|}{ Endline survey } \\
\hline Number of participants at end line & 1566 & 1515 & 3081 \\
\hline Median [IQR] age of participants in years & $10(8-12)$ & $10(8-12)$ & $10(8-12)$ \\
\hline Female sex & $791(51)$ & $786(52)$ & $1577(51)$ \\
\hline \multicolumn{4}{|l|}{ Participant currently lives with } \\
\hline Both parents & $1024(65)$ & $932(62)$ & $1956(63)$ \\
\hline Single parent & $268(17)$ & $294(19)$ & $562(18)$ \\
\hline Guardian & $274(17)$ & $289(19)$ & $563(18)$ \\
\hline $\begin{array}{l}\text { Participants who received worm treatment during the deworming } \\
\text { campaign at start of the study }\end{array}$ & $1457(93)$ & $1328(88)$ & $2785(90)$ \\
\hline $\begin{array}{l}\text { Participant ever received worm treatment somewhere else rather } \\
\text { than at school }\end{array}$ & $390(25)$ & $421(28)$ & $811(26)$ \\
\hline Participants who had a latrine at home & $1559(99.6)$ & $1512(99.8)$ & $3071(99.7)$ \\
\hline \multicolumn{4}{|l|}{ Type of latrine } \\
\hline Latrine uses flushed water & $531(34)$ & $519(34)$ & $1050(34)$ \\
\hline
\end{tabular}


Table 2 Characteristics of individual participants within the clusters randomised to the intervention or control arm of the Mikono Safi trial, Kagera region, Tanzania (Continued)

\begin{tabular}{|c|c|c|c|}
\hline & Intervention $n$ (\%) & Control $n(\%)$ & Total $n(\%)$ \\
\hline Latrine has a hole in the floor & $1231(79)$ & $1158(76)$ & $2389(78)$ \\
\hline Latrine has a hole in the floor and a lid to cover the hole & $421(27)$ & $424(28)$ & $845(28)$ \\
\hline Latrine with a ventilation pipe & $566(36)$ & $562(37)$ & $1128(37)$ \\
\hline Reported diarrhoea episode over the past 7 days & $373(24)$ & $337(22)$ & $710(23)$ \\
\hline Participant reported that they had ever eaten soil & $622(40)$ & $602(40)$ & $1224(40)$ \\
\hline Participant reported that they had ever observed worms while passing stool & $728(46)$ & $745(49)$ & $1473(48)$ \\
\hline
\end{tabular}

last time they washed hands at home, $45 \%$ of children in the intervention arm and 33\% in the control arm reported having used water and soap $(\mathrm{aOR}=1.02$, 95\%CI $0.74-1.39, p=0.90)$.

For the primary outcome measure at project end-line, the combined prevalence of Ascaris lumbricoides and Trichuris trichiura infection was 39\% in both trial arms $(\mathrm{aOR}=1.19 ; 95 \% \mathrm{CI} 0.74-1.91)$ (Table 3$)$. The prevalence of Ascaris lumbricoides infection alone was $15 \%$ in the intervention arm and $17 \%$ in the control arm (aOR = 1.24, 95\%CI 0.59-2.59). The prevalence of Trichuris trichiura infection was $31 \%$ in both trial arms $(\mathrm{aOR}=1.17$, 95\%CI 0.73-1.88). There were no significant differences in the mean egg count between trial arms. For Ascaris lumbricoides, the cluster-level mean egg count was 150 eggs/gram $( \pm 105)$ in the intervention arm and 305 eggs/ gram $( \pm 350)$ in the control arm (aOR $0.84 \quad 0.29-2.37$ ), respectively. For Trichuris trichiura, these data were 16 $( \pm 6)$ and $34( \pm 19)$ eggs/gram, respectively (aOR 0.96; $95 \%$ CI $0.53-1.76)$. Only $1 \%$ of participants had evidence of hookworm infection, with no difference between trial arms.

A total of 672 school children participated in the substudy on hand contamination, 336 from each arm (Table 4). None of the children were found to have their hands contaminated with eggs of Trichuris trichiura infection, while $6 \%$ and $10 \%$ of students from the intervention and control arms, respectively, had their hands contaminated with eggs of Ascaris lumbricoides ( $\mathrm{OR}=$ 0.84, 95\%CI 0.39-1.81). Few children had evidence of

Table 3 Effect of hand washing intervention on soil-transmitted helminth prevalence, infection intensity and handwashing behaviour at end-line survey in the Mikono Safi trial, Kagera region, Tanzania

\begin{tabular}{|c|c|c|c|c|c|}
\hline & $\begin{array}{l}\text { Intervention } \\
(N=1566)\end{array}$ & $\begin{array}{l}\text { Control } \\
(N=1515)\end{array}$ & $\begin{array}{l}\text { Crude OR } \\
(95 \% \mathrm{Cl})\end{array}$ & $\begin{array}{l}\mathrm{aOR}^{\mathrm{ab}} \\
(95 \% \mathrm{Cl})\end{array}$ & $\begin{array}{l}P \\
\text { value }\end{array}$ \\
\hline & $n(\%)$ & $n(\%)$ & & & \\
\hline \multicolumn{6}{|l|}{ Primary outcome ${ }^{b}$} \\
\hline Combined Ascaris lumbricoides and/or Trichuris trichiura infection & $603(39)$ & $585(39)$ & $\begin{array}{l}0.99(0.60- \\
1.63)\end{array}$ & $\begin{array}{l}1.19(0.74- \\
1.91)\end{array}$ & 0.466 \\
\hline Ascaris lumbricoides infection prevalence & $242(15)$ & $259(17)$ & $\begin{array}{l}0.90(0.39- \\
2.09)\end{array}$ & $\begin{array}{l}1.24(0.59- \\
2.59)\end{array}$ & 0.547 \\
\hline Trichuris trichiura infection prevalence & $479(31)$ & $464(31)$ & $\begin{array}{l}0.99(0.60- \\
1.64)\end{array}$ & $\begin{array}{l}1.17(0.73- \\
1.88)\end{array}$ & 0.501 \\
\hline \multicolumn{6}{|l|}{ Secondary outcomes ${ }^{c}$} \\
\hline Hookworm infection & $11(1)$ & $13(1)$ & - & - & - \\
\hline Participants reporting using soap and water during last hand washing occasion & $910(58)$ & $529(35)$ & $\begin{array}{l}1.68(1.18- \\
2.39)\end{array}$ & $\begin{array}{l}1.76(1.28- \\
2.43)\end{array}$ & 0.001 \\
\hline \multicolumn{6}{|l|}{ Reported location of last handwashing episode } \\
\hline School & $746(48)$ & $393(26)$ & $\begin{array}{l}1.84(1.13- \\
3.00)\end{array}$ & $\begin{array}{l}1.81(1.12- \\
2.93)\end{array}$ & 0.011 \\
\hline Home/did not remember location/other location & $820(52)$ & $1122(74)$ & 1.0 & 1.0 & \\
\hline $\begin{array}{l}\text { Participants used soap and water during most recent hand washing occasion in } \\
\text { school }[\boldsymbol{n} / \boldsymbol{N}(\%)]\end{array}$ & $538 / 746(72)$ & $\begin{array}{l}154 / 393 \\
(39)\end{array}$ & $\begin{array}{l}3.42(1.27- \\
9.22)\end{array}$ & $\begin{array}{l}3.7(1.35- \\
10.15)\end{array}$ & 0.002 \\
\hline $\begin{array}{l}\text { Participants used soap and water during most recent hand washing occasion at } \\
\text { home }[n / N(\%)]\end{array}$ & $372 / 820(45)$ & $\begin{array}{l}375 / 1122 \\
(33)\end{array}$ & $\begin{array}{l}0.97(0.69- \\
1.37)\end{array}$ & $\begin{array}{l}1.02(0.74- \\
1.39)\end{array}$ & 0.904 \\
\hline
\end{tabular}

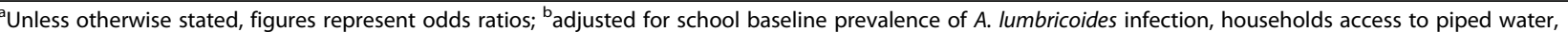
hand washing with soap before eating and after using the toilet and soil eating behaviour; 'adjusted for school aggregated households' access to piped water at baseline only 
Table 4 Effect of handwashing intervention on hand contamination with soil-transmitted helminths and coliform bacteria in the Mikono Safi trial, Kagera region, Tanzania

\begin{tabular}{|c|c|c|c|c|}
\hline & $\begin{array}{l}\text { Intervention }(N=336) \\
n(\%)\end{array}$ & $\begin{array}{l}\text { Control }(N=336) \\
n(\%)\end{array}$ & OR $(95 \% \mathrm{Cl})$ & $\begin{array}{l}P \\
\text { value }\end{array}$ \\
\hline Participants with Ascaris lumbricoides hand contamination & $21(6)$ & $35(10)$ & $0.84(0.39-1.81)$ & 0.646 \\
\hline Participants with hookworm hand contamination & $3(1)$ & $7(2)$ & $0.97(0.16-5.77)$ & 0.970 \\
\hline Hand contamination with coliforms & $154(46)$ & $171(51)$ & $0.90(0.55-1.46)$ & 0.642 \\
\hline Moderate or high ${ }^{\mathrm{a}}$ intensity hand contamination with coliform & $61 / 154(40)$ & $95 / 171(56)$ & $0.67(0.26-1.73)$ & 0.451 \\
\hline Hand contamination with Escherichia coli & $21(6)$ & $21(6)$ & $1.07(0.45-2.55)$ & 0.859 \\
\hline Moderate or high ${ }^{a}$ intensity hand contamination with Escherichia coli & $5 / 21(43)$ & $12 / 21(86)$ & $0.74(0.14-3.94)$ & 0.727 \\
\hline
\end{tabular}

${ }^{a}$ The quantification of total coliforms and Escherichia coli was categorised into mild $\left(\leq 9 \times 10^{3} \mathrm{CFU} / \mathrm{ml}\right)$, moderate $\left(10-99 \times 10^{3} \mathrm{CFU} / \mathrm{ml}\right)$, and high $\left(\geq 100 \times 10^{3} \mathrm{CFU} /\right.$ $\mathrm{ml}$ ) intensities. Mild intensity infection used as reference for comparison of infection intensity

contamination with hookworm eggs, without significant difference between trial arms. We also did not observe significant differences between trial arms on the level of hand contamination with both coliform bacteria and Escherichia coli. There was a trend towards a lower intensity of contamination with regards to both coliform bacteria and Escherichia coli in the intervention arm; however, none of these differences were statistically significant.

\section{Discussion}

This trial assessed the potential effect of a hand hygiene intervention package on the prevalence and intensity of Ascaris lumbricoides and Trichuris trichiura infections among primary school children aged 6 to 12 years, 12 months after deworming using a single dose of albendazole. We had earlier shown that the intervention was well accepted by teachers, parents and children [23]. We found that the intervention resulted in increased reporting of handwashing with water and soap at school, but had failed to reduce the prevalence or intensity of any of the STH infections investigated. This might be due a number of reasons, including ineffectiveness of the handwashing intervention to reduce transmission in a school setting, occasional supply problems at schools with regard to the availability of water for handwashing, infections occurring in the home environment, alternative routes of STH transmission e.g. through contaminated food or drinking water or ingestion of soil, ineffectiveness of the MDA strategy with respect to Trichuris trichiura infection, and a lower than complete coverage of the MDA strategy due to absenteeism of some students. These results suggest that the education and hardware-based intervention to promote handwashing in schools and homes as delivered in this trial was not effective in reducing the burden of STH infections among school children when given in the context of routine deworming.

While the initial deworming successfully reduced the prevalence of Ascaris lumbricoides infection, it had no effect on Trichuris trichiura infections in spite of retreating remaining STH infections after the baseline survey. On the basis of these findings, we conclude that the MDA strategy currently used in Tanzania was not effective in reducing the burden of this infection. The lack of an effect of single dose albendazole treatment on Trichuris trichiura has been described by others [24]. We recommend the current MDA strategy for schools in Tanzania should be revised based on these findings.

There are several plausible explanations for the lack of observed effect of the handwashing intervention in our study. First, the handwashing intervention alone may not have been sufficient to reduce STH transmission within the school environment. While an association between handwashing promotion and STH infections has been observed in a range of observational and intervention studies $[9,10]$, in two recent trials from rural Kenya [25] and Bangladesh [26], handwashing intervention alone was not found to reduce STH infections. In contrast, a combined water improvement, sanitation and handwashing intervention package was shown to be effective [25, 26]. This suggests that hand hygiene interventions could contribute to the sustainable control of STH infections in settings of ongoing deworming programmes when provided as part of an integrated package, including water quality improvements and sanitation.

Second, our intervention may not have improved handwashing behaviours enough to provide an independent protective effect against STH transmission. Data on handwashing behaviour were based on self-reports and could be affected by desirability bias which may have differentially favoured intervention schools. To avoid this, we had originally planned to also systematically observe handwashing behaviour after children had visited the toilet. When this was piloted, we realised that the presence of the observer was akin to an intervention on its own and we abandoned this strategy. We can therefore not rule out that the intervention may have been weaker with regards to its effect on reported hygiene behaviour than our data suggest. The observed 
lack of an intervention effect on hand contamination with coliform bacteria and with Escherichia coli would lend support to this interpretation, although we saw a trend towards lower infection intensity in the intervention arm.

At schools, our intervention consisted of hygiene promotion intervention targeting children focused on three teacher-lead sessions incorporating hygiene education and games accompanied by new handwashing stations and other small-scale infrastructural changes. This intervention was deliberately designed to be replicable and scalable by the local education system without larger financial investments. The average investment and maintenance costs were GBP 88.2 per handwashing facility. The production was done by local craftsmen using locally available materials. Major repairs were not needed during the duration of the study. The compromise in intervention intensity made to promote scalability resulting in a lack of behavioural or health impact has been observed in other handwashing trials in domestic settings [27]. Specifically, the Mikono Safi intervention may not have been sufficient to allow for routine handwashing among children. A qualitative study of student and teacher participating in the Mikono Safi intervention found high rates of knowledge and strong motivation for handwashing among students [23]. However, this same study found that water and soap for use in handwashing were not consistently available to students, either due to periodic disruptions in water supply or because soap was not reliably available for students to use. Students in the intervention group may not have been able to wash hands frequently enough to interrupt pathogen transmission.

Third, other factors may have contributed to reinfection after deworming. While parents were given information on the transmission routes of helminth infections along with advice about actions they could take at home to protect children, changes in the domestic environment were modest and focused primarily on improving sanitation infrastructure (manuscript in development). The environment at home may, therefore, have been an important source of recontamination independent of any school-based improvements. We cannot rule out that other environmental transmission routes may have played a role: contaminated drinking water has been observed as a possible source of infection elsewhere [28], and this may have occurred also in our study given that the majority of households depended on unprotected springs and rivers which may pose a risk of STH infection. Contaminated food may also have contributed, in particular insufficiently cleaned vegetables or fruit $[29,30]$. High proportion of students reported eating soil, and this may have contributed to helminth re-infection and episodes of diarrhoea. It is also possible that students from schools in the control arm in Bukoba town may have had contact with school mates from schools allocated to the intervention arm. This may have diluted any measurable intervention effect. However, in rural areas, the distance between communities were large and contamination nearly impossible, and because there was not even a trend suggesting an intervention effect, we feel that contamination is an unlikely explanation for the observed lack of effect.

A major strength of our study was its design, i.e. a cluster randomised trial with a large sample size. Another strength was that at the planning stage pre-trial data had been available on STH prevalence from 51 schools in the region. The co-efficient of variation could therefore be determined and inform sample size calculations, and schools with comparatively low STH prevalence excluded thereby increasing power of the study to detect a potential intervention effect. Furthermore, our handwashing intervention combined classical information giving, subconscious behaviour modification through environmental nudges and emotional engagement of parents and was therefore well-designed to trigger the desired behaviour change. Lastly, the long follow-up period of 12 months between deworming and end-line assessment allowed to study intervention effects beyond potentially short-lived behaviour modifications.

A major limitation of the study was its inability to causatively assess the potential role of the handwashing intervention on the transmission of Trichuris trichiura infection, due to the failure of single-dose treatment with $400 \mathrm{mg}$ of albendazole to eliminate this specific STH. We informed the national NTD control programme, recommending a revision of the treatment regimen. Another limitation was that data on handwashing behaviour was based on self-reports and could be affected by desirability bias which may have differentially affected our results in the two trial arms. Furthermore, there was a slightly higher proportion of participants who did not provide stool samples at end-line in the control arm, and this could have introduced some selection bias. However, there was no evidence that collection of stool samples at end-line differed between intervention and control groups.

\section{Conclusions}

In conclusion, the Mikono Safi handwashing intervention has been effective in fostering reported handwashing at school. While it was hoped that the intervention may also lead to an improvement of handwashing behaviour in the home, self-reports did not show such a secondary effect. Importantly, the intervention did not show the desired effect on maintaining the success of MDA on STH infection, probably due to infection occurring in the home environment and possibly due to other transmission routes which may have included contaminated water or food. 


\section{Acknowledgements}

We are grateful to the Ethics Committees of the Tanzania National Institute for Medical Research and the London School of Hygiene and Tropical Medicine (LSHTM) for the permission to conduct this trial. We thank the health and education authorities of Kagera region for their permission to conduct the study and for their support with human resources and facilities. We are indebted to the students, teachers and parents who enthusiastically participated in the study.

\section{Authors' contributions}

The trial was designed by JE, Ska, HG, CH, KM and Ski. Sample size estimates and randomisation procedures were guided by $\mathrm{CH}$ with inputs from $\mathrm{HG}$. The trial was coordinated by $\mathrm{KM}$ and was implemented with input from $\mathrm{OM}, \mathrm{HG}$, PA, Ski and Ska. RD, SR and EO designed and conducted the formative research and contributed in the design of the intervention. Baseline and end-line survey activities were coordinated by SS and KM. Hand contamination sub-study was coordinated by HM and JS. Laboratory work was planned and supervised by Ski with support from JM. Data analysis was performed by PA. KM, HG and Ska drafted the manuscript. All co-authors contributed critically to the manuscript and approved the final version.

\section{Funding}

We thank the UK Department for International Development (DIFD) for funding this project through the Sanitation and Hygiene Applied Research for Equity (SHARE) Consortium based at the London School of Hygiene and Tropical Medicine. The funder had no role in the trial design, data collection, data analysis, data interpretation, or writing of the report.

\section{Availability of data and materials}

De-identified participant data analysed in this report are available and can be assessed at an online data repository [31].

\section{Declarations}

\section{Ethics approval and consent to participate}

The trial was approved by the ethics committees of the Tanzania National Institute for Medical Research (Ref: NIMR/HQ/R.8a/Nol. IX/2497) and the London School of Hygiene and Tropical Medicine (Ref: LSHTM 11868). Ethics committees approved the opt-out strategy for parent/guardian consent and provided a waiver of consent and assent for students' participation in the intervention because hygiene-related health education and deworming campaigns should be routinely conducted at primary schools in Tanzania. For the effectiveness evaluation, all participating students were invited to provide informed written assent prior to enrolment in the surveys. Students who were not yet able to read and write could give verbal assent which was confirmed in writing by a witnessing teacher. Parents or guardians were invited to provide informed consent based on a circulated information leaflet, using an opt-out strategy for those who did not wish their children to participate. Students were given autonomy to withdraw from the evaluation surveys at any point if they wished.

\section{Consent for publication}

Not applicable.

\section{Competing interests}

The authors declare that they have no competing interests.

\section{Author details}

${ }^{1} M$ wanza Intervention Trials Unit (MITU), Mwanza, Tanzania. ${ }^{2}$ London School of Hygiene and Tropical Medicine, London, UK. ${ }^{3}$ National Institute for Medical Research (NIMR), Mwanza, Tanzania. ${ }^{4}$ Department of Medical Parasitology and Entomology, Catholic University of Health and Allied Sciences (CUHAS), Mwanza, Tanzania. ${ }^{5}$ Department of Microbiology and Immunology, Catholic University of Health and Allied Sciences (CUHAS), Mwanza, Tanzania. ${ }^{6}$ Johns Hopkins Bloomberg School of Public Health, Baltimore, Maryland, USA.
Received: 25 January 2021 Accepted: 19 April 2021

Published online: 21 May 2021

\section{References}

1. World Health Organization. Soil-transmitted halminthiases: STH : eliminating soil-transmitted helminthiases as a public health problem in children : progress report 2001-2010 and strategic plan 2011-2020. Geneva: World Health Organization; 2012.

2. Bethony J, Brooker S, Albonico M, Geiger SM, Loukas A, Diemert D, et al. Soil-transmitted helminth infections: ascariasis, trichuriasis, and hookworm. Lancet. 2006;367(9521):1521-32. https://doi.org/10.1016/S0140-673 6(06)68653-4.

3. Koukounari A, Estambale BBA, KiamboNjagi J, Cundill B, Ajanga A, Crudder C, et al. Relationships between anaemia and parasitic infections in Kenyan schoolchildren: a Bayesian hierarchical modelling approach. Int J Parasitol. 2008;38(14):1663-71. https://doi.org/10.1016/j.jpara.2008.05.013.

4. United Republic of Tanzania M of E and VT. National Strategic Plan for School Water, Sanitation and Hygiene (SWASH) 2012 - 2017. 2011. Available from: http://www.unesco.org/education/edurights/media/docs/39d043c23 67b728dd6580cc173bb4ce26e2f80f7.pdf

5. Brooker S, Kabatereine NB, Smith JL, Mupfasoni D, Mwanje MT, Ndayishimiye $\mathrm{O}$, et al. An updated atlas of human helminth infections: the example of East Africa. Int J Health Geogr. 2009;8(1):42. https://doi.org/10.11 86/1476-072X-8-42.

6. Siza JE, Kaatano GM, Chai J-Y, Eom KS, Rim H-J, Yong T-S, et al. Prevalence of schistosomes and soil-transmitted helminths and morbidity associated with schistosomiasis among adult population in Lake Victoria Basin. Tanzania Korean J Parasitol. 2015;53(5):525-33. https://doi.org/10.3347/kjp.2 015.53.5.525.

7. Yap P, Du Z-W, Wu F-W, Jiang J-Y, Chen R, Zhou X-N, et al. Rapid reinfection with soil-transmitted helminths after triple-dose albendazole treatment of school-aged children in Yunnan, People's Republic of China. Am J MedHyg. 2013;89(1):23-31. https://doi.org/10.4269/ajtmh.13-0009.

8. Ziegelbauer K, Speich B, Mäusezahl D, Bos R, Keiser J, Utzinger J. Effect of sanitation on soil-transmitted helminth infection: systematic review and meta-analysis. PLOS Med. 2012;9(1):e1001162. https://doi.org/10.1371/journa I.pmed.1001162

9. Strunz EC, Addiss DG, Stocks ME, Ogden S, Utzinger J, Freeman MC. Water, sanitation, hygiene, and soil-transmitted helminth infection: a systematic review and meta-analysis. PLoS Med. 2014;25:11(3) Available from: https:// www.ncbi.nlm.nih.gov/pmc/articles/PMC3965411/.

10. Vaz Nery S, Pickering AJ, Abate E, Asmare A, Barrett L, Benjamin-Chung J, et al. The role of water, sanitation and hygiene interventions in reducing soil-transmitted helminths: interpreting the evidence and identifying next steps. Parasit Vectors. 2019;12(1):273. https://doi.org/10.1186/s13071-019-3 532-6.

11. National Beureau of Statistics M of F. United Republic of Tanzania, Population and Housing Census. Dar es Salaam. Marp. 2012;2013:163-71 Available from: http://www.tzdpg.or.tz/fileadmin/documents/dpg_internal/ dpg_working_groups_clusters/cluster_2/water/WSDP/Background_informa tion/2012_Census_General_Report.pdf.

12. Joshi AR, Gaddis I,. Preparing the next generation in Tanzania: challenges and opportunities in education. The World Bank; 2015. Available from: http://elibrary.worldbank.org/doi/book/10.1596/978-1-4648-0590-5

13. Makata K, Kinung'hi S, Hansen C, Ayieko P, Sichalwe S, Mcharo O, et al. Hand hygiene intervention to optimize helminth infection control: design and baseline results of Mikono Safi-An ongoing school-based clusterrandomised controlled trial in NW Tanzania. PLoS One. 2020;15(12): e0242240. https://doi.org/10.1371/journal.pone.0242240.

14. Hulland KR, Leontsini E, Dreibelbis R, Unicomb L, Afroz A, Dutta NC, et al. Designing a handwashing station for infrastructure-restricted communities in Bangladesh using the integrated behavioural model for water, sanitation and hygiene interventions (IBM-WASH). BMC Public Health. 2013;13(1):877. https://doi.org/10.1186/1471-2458-13-877.

15. Dreibelbis $R$, Kroeger A, Hossain K, Venkatesh M, Ram PK. Behavior change without behavior change communication: nudging handwashing among primary school students in Bangladesh. Int J Environ Res Public Health. 2016 Jan;13(1):129. https://doi.org/10.3390/ijerph13010129.

16. Grover E, Hossain MK, Uddin S, Venkatesh M, Ram PK, Dreibelbis R. Comparing the behavioural impact of a nudge-based handwashing intervention to high-intensity hygiene education: a cluster-randomised trial 
in rural Bangladesh. Trop Med Int Health. 2018;23(1):10-25. https://doi.org/1 $0.1111 /$ tmi.12999.

17. Body shields as disease protectors: formative research in Tanzania | share research. 2017. Available from: https://www.shareresearch.org/body-shieldsdisease-protectors-formative-research-tanzania

18. Elgendy AM, Mohammed FA, Metwally AS, Hamza RS, Kamel S. Comparison between Kato - Katz thick smear and sedimentation techniques in diagnosis of faecal - orally transmitted helminthes and other geohelminthes. J Egypt Soc Parasitol. 2016 Dec;240(4028):1-8.

19. Young KH, Bullock SL, Melvin DM, Spruill CL. Ethyl acetate as a substitute for diethyl ether in the formalin-ether sedimentation technique. J Clin Microbilol. 1979;10(6):852-3. https://doi.org/10.1128/JCM.10.6.852-853.1979.

20. Koneman EW, Allen SD, Janda WM, Schreckenberger PC, Winn WC. Colour Atlas and textbook of diagnostic microbiology. 5th ed. Philadelphia: Lippincott. Williams\&Wilkins; 1997.

21. Faust EC, Sawitz W, Tobie J, Odom V, Peres C, Lincicome DR. Comparative efficiency of various techniques for the diagnosis of protozoa and helminth in feces. J Parasitol. 1939;25(3):241-62. https://doi.org/10.2307/3272508.

22. Hayes RJ, Moulton LH, Moulton LH. Cluster Randomised Trials: Chapman and Hall/CRC; 2009. Available from: https://www.taylorfrancis.com/books/ 9780429142055

23. Okello E, Kapiga S, Grosskurth H, Makata K, Mcharo O, Kinungh'i S, et al. Factors perceived to facilitate or hinder handwashing among primary students: a qualitative assessment of the Mikono Safi intervention schools in NW Tanzania. BMJ Open. 2019;9(11):e030947. https://doi.org/10.1136/ bmjopen-2019-030947.

24. Keiser J, Utzinger J. Efficacy of current drugs against soil-transmitted helminth infections: systematic review and meta-analysis. JAMA. 2008; 299(16):1937-48. https://doi.org/10.1001/jama.299.16.1937.

25. Pickering AJ, Njenga SM, Steinbaum L, Swarthout J, Lin A, Arnold BF, et al. Effects of single and integrated water, sanitation, handwashing, and nutrition interventions on child soil-transmitted helminth and Giardia infections: a cluster-randomized controlled trial in rural Kenya. PLoS Med. 2019;26, 16(6) Available from: https://www.ncbi.nlm.nih.gov/pmc/articles/ PMC6594579/

26. Ercumen A, Benjamin-Chung J, Arnold BF, Lin A, Hubbard AE, Stewart C, et al. Effects of water, sanitation, handwashing and nutritional interventions on soil-transmitted helminth infections in young children: a clusterrandomized controlled trial in rural Bangladesh. PLoS Negl Trop Dis. 2019; 13(5):e0007323. https://doi.org/10.1371/journal.pntd.0007323.

27. Biran A, White S, Awe B, Greenland K, Akabike K, Chuktu N, et al. A clusterrandomised trial to evaluate an intervention to promote handwashing in rural Nigeria. International Journal of Environmental Health Research. 2020: 1-16. https://doi.org/10.1080/09603123.2020.1788712.

28. Jonnalagadda PR, Bhat RV. Parasitic contamination of stored water used for drinking/cooking in Hyderabad. Southeast Asian J Trop Med Public Health. 1995;26(4):789-94.

29. Ensink JHJ, Mahmood T, Dalsgaard A. Wastewater-irrigated vegetables: market handling versus irrigation water quality. Trop. Med. Int Health. 2007; 12(s2):2-7. https://doi.org/10.1111/j.1365-3156.2007.01935.x.

30. Bekele F, Tefera T, Biresaw G, Yohannes T. Parasitic contamination of raw vegetables and fruits collected from selected local markets in Arba Minch town, Southern Ethiopia. Infect Dis Poverty. 2017;6(1):1-7.

31. Ayieko P, Hashim R, Grosskurth H, Kapiga S. Hand hygiene intervention to optimise soil transmitted helminths infection control among primary school children: endline survey data from a cluster randomised trial. Mendeley Data. 2021;1. https://doi.org/10.17632/9wgnn35jcr.1.

\section{Publisher's Note}

Springer Nature remains neutral with regard to jurisdictional claims in published maps and institutional affiliations.

Ready to submit your research? Choose BMC and benefit from:

- fast, convenient online submission

- thorough peer review by experienced researchers in your field

- rapid publication on acceptance

- support for research data, including large and complex data types

- gold Open Access which fosters wider collaboration and increased citations

- maximum visibility for your research: over $100 \mathrm{M}$ website views per year

At BMC, research is always in progress.

Learn more biomedcentral.com/submissions 